\title{
EXPERIMENTAL CRACK PROPAGATION ANALYSIS OF THE COMPRESSOR BLADES WORKING IN HIGH CYCLE FATIGUE CONDITION
}

\author{
Lucjan Witek \\ Rzeszów University of Technology \\ Rzeszów, Poland
}

\begin{abstract}
This paper presents results of experimental vibration tests of the helicopter turbo-engine compressor blades. The blades used in investigation were retired from maintenance under technical inspection of engine. Investigations were conducted for selected undamaged blades, without existence of preliminary cracks or corrosion pits. The blades during experiment were entered into transverse vibration. The crack propagation process was conducted in resonance condition. During the fatigue test, the growth of crack was monitored. In the second part of work, a nonlinear finite element method was utilized to determine the stress state of the blade during vibration. In this analysis a first mode of transverse vibration were considered. High maximum principal stress zone was found at the region of blade where the crack occurred.
\end{abstract}

Keywords: Compressor blade; Failure analysis; Crack propagation; Vibration; FEM.

\section{INTRODUCTION}

High-speed rotating compressor components are susceptible to many kinds of problems. One of the problems that has plagued the jet engine manufactures for decades is failure due to High Cycle Fatigue. High Cycle Fatigue, commonly referred to as HCF, is the fatigue of rotating components brought on mainly by dynamic forces caused by vibration. HCF is always concerned with rotation of unbalanced shaft or compressor/turbine disc. Moreover the HCF condition also occurs during passing of blades by non uniform stream of air produced by blade cascade.

High Cycle Fatigue failures typically have a root cause which stems from flaws in the material (impurities or voids), abusive machining which creates high stress concentrations, or wear between components. However, even ,perfect” components have a finite life, and will fail after a certain number of cycles. If a problem arises in the compressor section it will significantly affect the whole engine function and, of course, safety of the aircraft. The blade broken could cause to puncture of the engine casing. Failures of any high speed rotating components (jet engine rotors, centrifuges, high speed fans, etc.) can be very dangerous to passengers, personnel and surrounding equipment and must always be avoided.

In the case of an old aircraft or helicopters, which are operated according to damage tolerance philosophy, information about crack growth rate is very important. In aerospace engineering, structure is considered to be damage tolerant if a maintenance program has been implemented that will result in the detection and repair of accidental damage, corrosion and fatigue cracking before such damage degrades structural strength below an acceptable limit. On the base of crack growth rate, the time between obligatory technical inspection of engine component can be defined. 
The failure analysis of the compressor blade has received the attention of several investigations. The problem of fatigue fracture of the compressor blade was described by: Lourenco at all [1], Kermanpur et al. [2], Silveira et al. [3] and Poznanska et al. [4]. The work's condition of the turbine blade are heavier by occurrence of the thermal and mechanical stress, thermal degradation of material, creep, erosion etc. For this reason more causes of the turbine blade damage are reported (Troshchenko et al. [5], Park et al. [6], Song et al. [7], Vardar et al. [8], $\mathrm{Xu}$ et al. [9], Song et al. [10], Xie et al. [11], Witek [12, 13]).

The idea for investigation presented in this paper was initiated during failure analysis of the compressor blade, ruptured under engine operation [14]. In this case an influence on the fatigue failure had two loads: pulsation of centrifugal forces during compressor rotation (low cycle fatigue, $\mathrm{LCF}$ ) and vibration (HCF).

In present paper the blades were tested in artificially created high cycle fatigue condition (vibration). By specify only one load component and analysis of experimental and numerical results, the complex fatigue failure process of compressor blades can be better understood. The additional goal of this investigation is to provide an answer on question: how fast the crack can propagate inside the structure.

\section{EXPERIMENTAL INVESTIGATIONS.}

The blades used in experimental fatigue tests were retired from maintenance under technical inspection of engine. After inspection, the blades were checked by fluorescent inspection method and next divided onto two groups: undamaged blades (retired by inadequate dimensional tolerance in results of erosion and polishing) and blades with existence of preliminary cracks or corrosion pits. In presented here investigations, the group of 10 undamaged blades was tested (Fig. 1). Experimental investigations were performed at Research and Development Laboratory for Aerospace Materials of Rzeszów University of Technology.

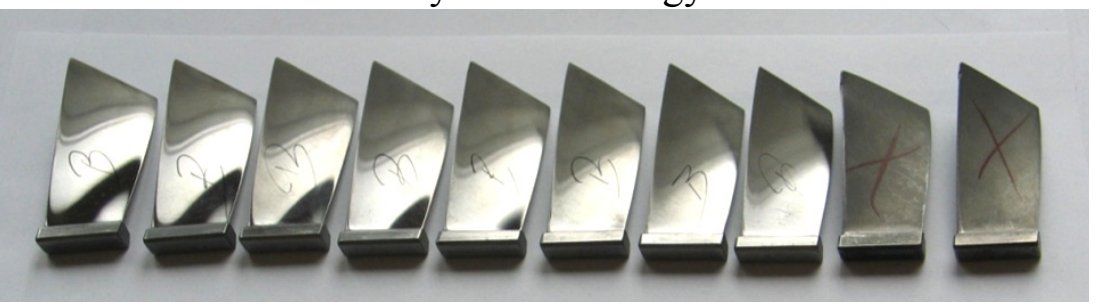

Fig. 1. Blades of the I-st stage compressor retired from maintenance under technical inspection of engine, destined for fatigue test.

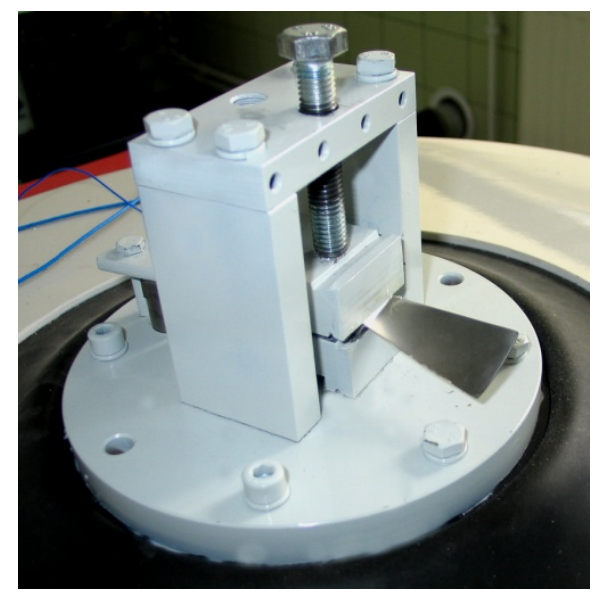

Fig. 2. View of the blade mounted on the movable head of the vibrator.

Before fatigue test, each blade was horizontally mounted on the movable head of vibrator (Fig. 2). After that, the head common with blade were entered into sinusoidal (harmonic) vibration. The 
investigation was started from searching resonance frequency (for I-st mode of transverse vibration). The fatigue test was started just from this frequency. During the test, both amplitude of vibration of the blade tip and the size (or existence) of the crack was periodically monitored. For control of amplitude the optical measuring microscope was used. Overall dimension of blade with crack initiation zone location and view of crack detected during fatigue test are presented in Fig. 3 . Investigations were conducted for different intensity of vibration, which was defined by amplitude of acceleration of the movable vibrator head. Amplitude of acceleration (excitation) was defined in $\mathrm{g}$ units, where $1 \mathrm{~g}$ equals $9,81 \mathrm{~m} / \mathrm{s}^{2}$. The fatigue tests were performed for intensity of vibration between $5 \div 25 \mathrm{~g}$.
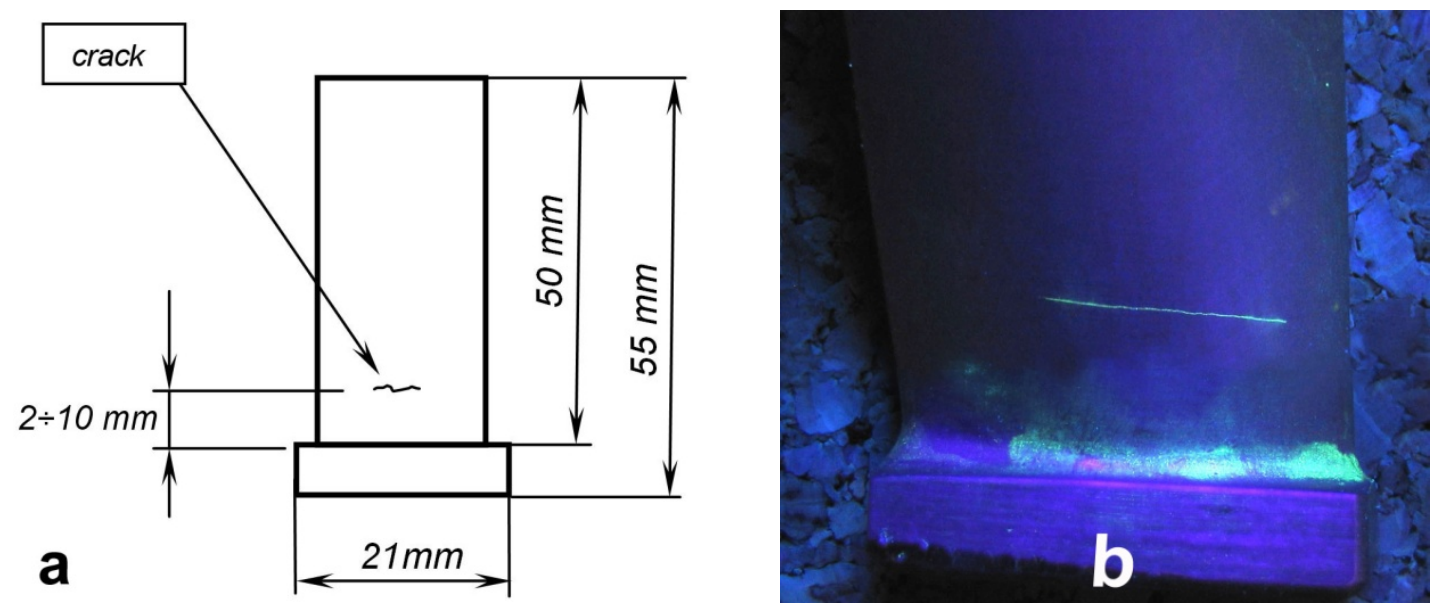

Fig. 3. Overall dimensions of the first stage blade of compressor with location of the cracks (a) and view of luminous crack in UV light (b).

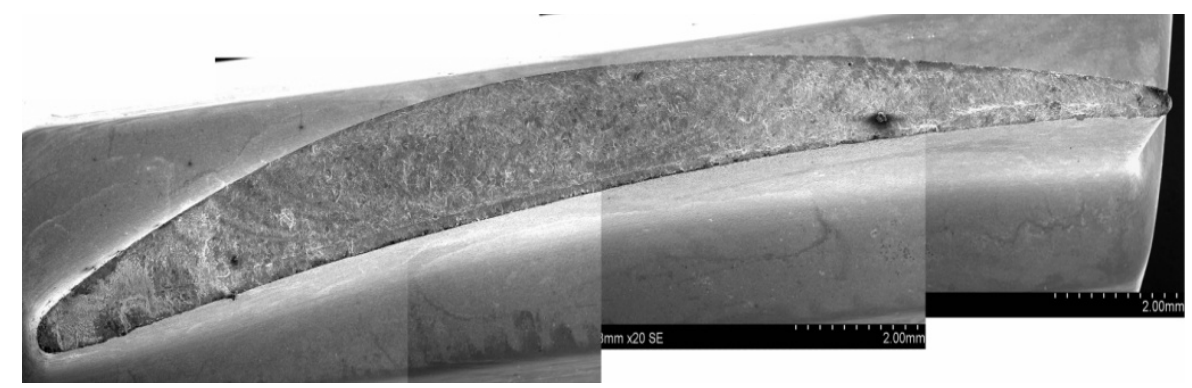

a)

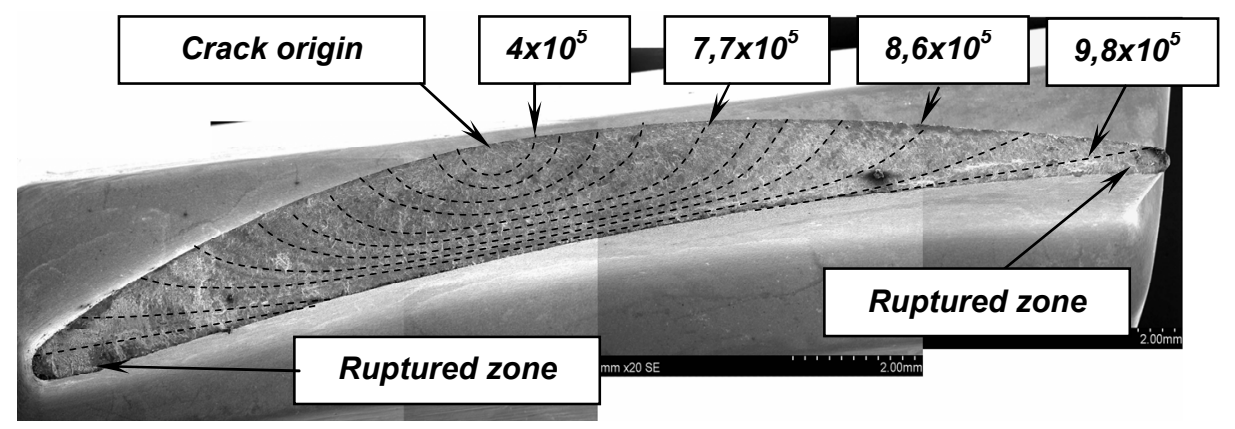

b)

Fig. 4. View of damaged blade (a). Fracture with marked beach marks, created by different number of cycles (b), blade no. 1.

Results presented in Fig. $4 \div 7$ and Tab. 1 are obtained from tests in which intensity of vibration was defined as 12g (for blades no. 1, 2 and 3). The fractured blade number 1 is shown in Fig. 4. 
The crack was initiated on the convex surface of profile, about $6 \mathrm{~mm}$ above the blade locking piece. The crack origin zone was not covered by corrosion product.

The control parameters of vibration system and results obtained for blade no. 1 are shown in Tab. 1. As seen from this table, the resonant frequency for blade is $774 \mathrm{~Hz}$, and from this frequency test was started. After $4 \times 10^{5}$ total number of cycles, an amplitude of blade tip decreased from $2,5 \mathrm{~mm}$ to $2,25 \mathrm{~mm}$. Under cracking, the bending stiffness of blade is decreased. This information is very important, because decrease of amplitude by constant intensity of excitation is often related with start of crack initiation process. In this case $1 \mathrm{~mm}$ long crack was detected. From the $6,76 \times 10^{5}$ number of cycles, the excitation frequency decreased with rate 0,2 and 1 $\mathrm{Hz} / \mathrm{sek}$. The crack length in function of the total number of cycles (crack growth plot), obtained for blade no. 1 is presented in Fig. 5.

Table 1. Control parameters of vibration system and results obtained for blade no. 1.

\begin{tabular}{|c|c|c|c|c|c|c|}
\hline $\begin{array}{c}\text { Initial } \\
\text { frequency }\end{array}$ & $\begin{array}{c}\text { Final } \\
\text { frequency }\end{array}$ & $\begin{array}{c}\text { Rate of change } \\
\text { of frequency }\end{array}$ & $\begin{array}{c}\text { Partial no. } \\
\text { of cycles }\end{array}$ & $\begin{array}{l}\text { Total no. } \\
\text { of cycles }\end{array}$ & $\begin{array}{l}\text { Crack } \\
\text { length }\end{array}$ & $\begin{array}{l}\text { Amplitude } \\
\text { of crack tip }\end{array}$ \\
\hline init $[\mathrm{Hz}]$ & $F_{\text {fin }}[\mathrm{Hz}]$ & df/dt [Hz/sek] & $N_{\text {part }} \times 10^{5}$ & $\mathrm{~N} \times 10^{5}$ & $\mathbf{a}[\mathrm{mm}]$ & $\mathbf{A}[\mathbf{m m}]$ \\
\hline 774 & 774 & 0 & 0 & 0,00 & 0 & 2,50 \\
\hline 774 & 774 & 0 & 1 & 1,00 & 0 & 2,50 \\
\hline 774 & 774 & 0 & 1 & 2,00 & 0 & 2,50 \\
\hline 774 & 774 & 0 & 1 & 3,00 & 0 & 2,47 \\
\hline 774 & 774 & 0 & 1 & 4,00 & 1 & 2,25 \\
\hline 774 & 774 & 0 & 1 & 5,00 & 2,5 & 1,75 \\
\hline 774 & 774 & 0 & 1 & 6,00 & 4,5 & 1,35 \\
\hline 770 & 750 & 0,2 & 0,76 & 6,76 & 6,3 & 1,20 \\
\hline 750 & 725 & 0,2 & 0,92 & 7,68 & 9 & 1,10 \\
\hline 725 & 700 & 0,2 & 0,89 & 8,57 & 12 & 1,05 \\
\hline 700 & 600 & 1 & 0,65 & 9,22 & 15 & 1,03 \\
\hline 600 & 500 & 1 & 0,55 & 9,77 & 19 & 1,03 \\
\hline
\end{tabular}

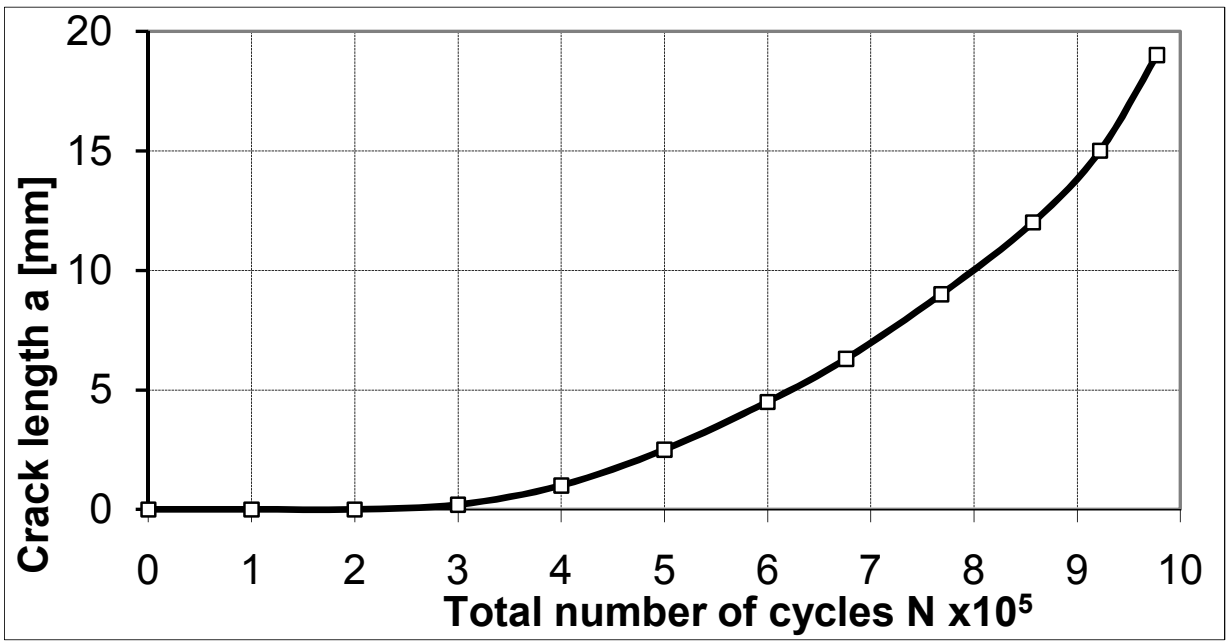

Fig. 5. Crack length in function of total number of cycles for I-st stage compressor blade (intensity of vibration 12g, blade no. 1).

The fatigue test for blade number 1 was conducted in short time and the crack was propagated in non-corrosive environment thus the beach marks presented in Fig. 4a are not well visible, 
especially around the crack origin zone. For better determine of crack front shape in the early stage of fracture, blade no. 2 was vibrated only to the first crack detection. Next the blade was statically tensioned and ruptured with use the testing machine.

Fig. 6 is a magnified view of the fractured surface. As seen from this figure, the crack front in the early stage of fatigue intensively moves inside the structure. The depth of crack (b dimension) is about $50 \%$ of total blade thickness. The fatigue fracture area is dark grey. A fluorescent penetrant was locally heated (in result of micro-friction during vibration) hence its black color around the crack origin zone. This color is not related with corrosion products.

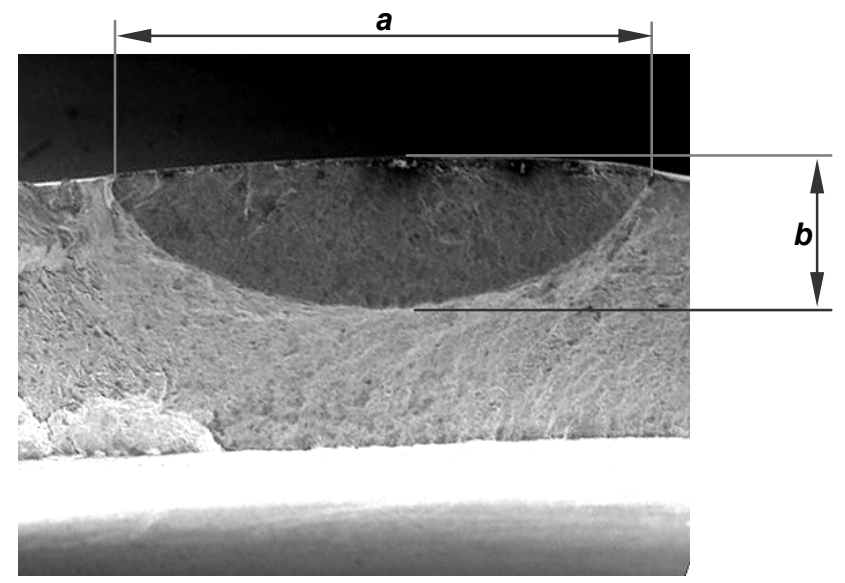

Fig. 6. Shape of crack front just after crack initiation (blade no. 2).

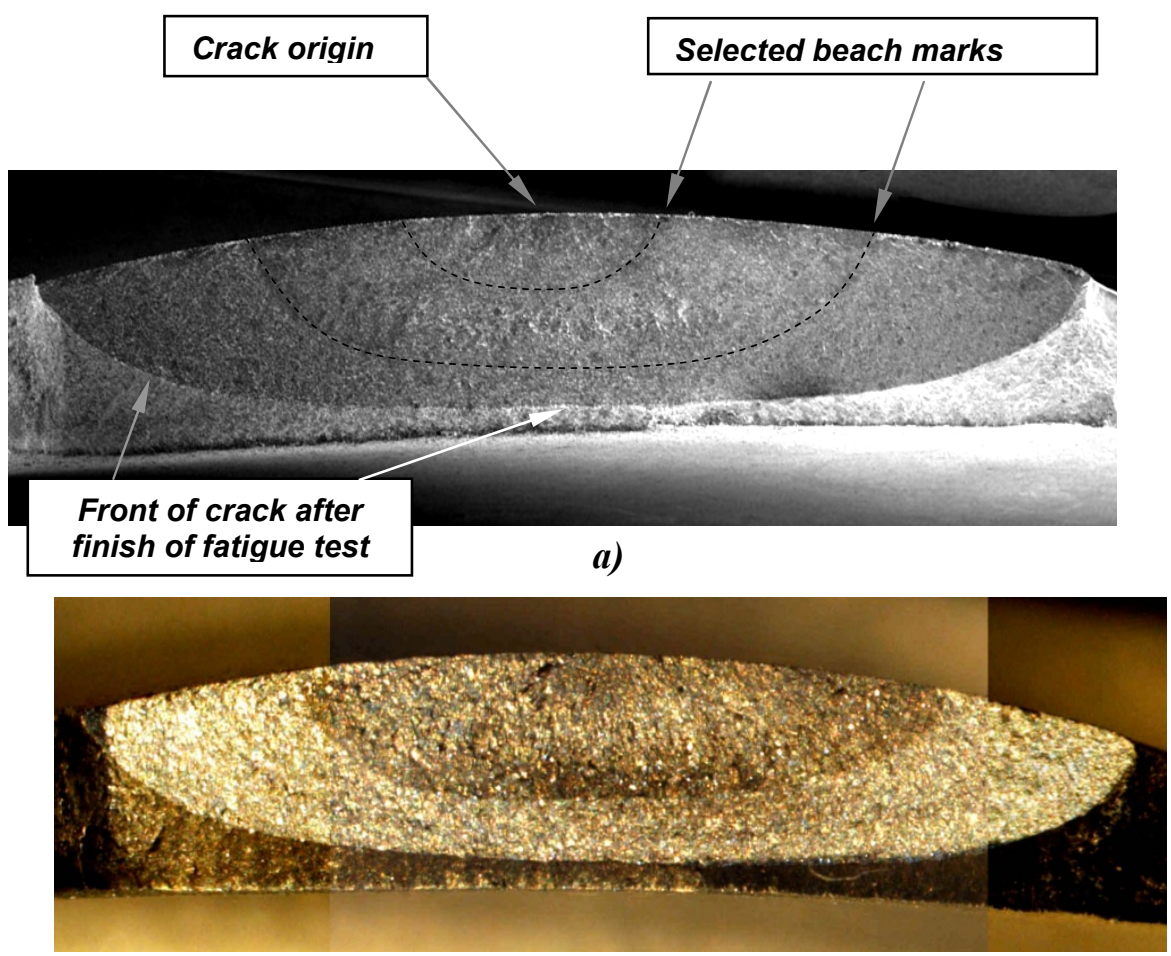

b)

Fig. 7. Shape of crack front in advanced phase of fatigue, after about $8 \times 10^{5}$ number of cycles, visible with use scaning (a) and optical (b) microscope (blade no. 3)

Blade number 3 was vibrated as long as the fatigue crack length (a dimension) was about 10 $\mathrm{mm}$. Next the blade was statically ruptured with use the testing machine. Shape of crack in advanced phase of growth is presented in Fig. 7. As seen from this figure, the crack in advanced 
phase of growth propagated quickly in the horizontal direction. By comparison Fig $7 \mathrm{a}$ and $7 \mathrm{~b}$ is visible that not scanning, but optical microscope is better for beach marks observation. Blade no. 3 was tested with about 3 month pause, hence on the fatigue fracture area are visible two different regions (dark around crack origin zone and bright).

In this paper, results for only three from ten blades were in detail described. The damage schemes of remaining blades are similar to presented in Fig. 4. The cracks were initiated on the convex surface of profile, from $2 \mathrm{~mm}$ to $10 \mathrm{~mm}$ above the blade locking piece (Fig. 8). The crack origin zones were not covered by corrosion product. In one case the crack was initiated from hole, which was made for fixing of the acceleration sensor (last blade presented in Fig. 8).

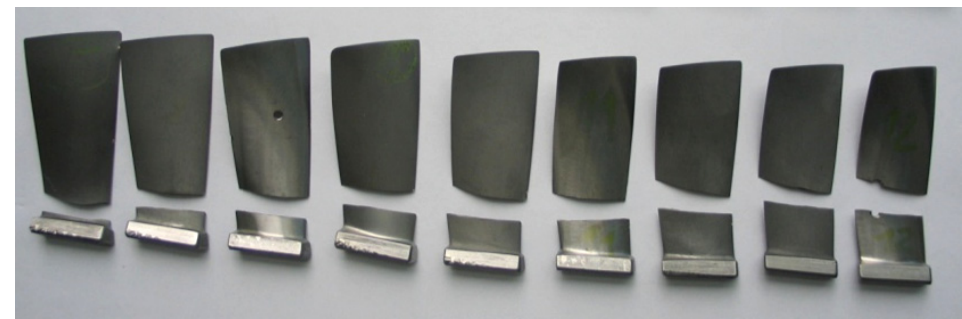

Fig. 8. Ruptured blades of the I-st stage of compressor after investigations (b).

\section{FINITE ELEMENT STRESS ANALYSIS OF THE BLADE IN RESONANCE CONDITION}

Computations for the blade, working in the vibration conditions were performed for analysis of stress state occurring during the blade resonance. In this analysis the first mode of transverse vibration was considered. Parametric geometry model of blade were made using the MSC-Patran program [15]. The FE model of blade presented in Fig. 9 consists of 4796 nodes and 3760 HEX-8 elements. For the free vibration analysis, the blade was fixed in the bottom surface of dovetail region.

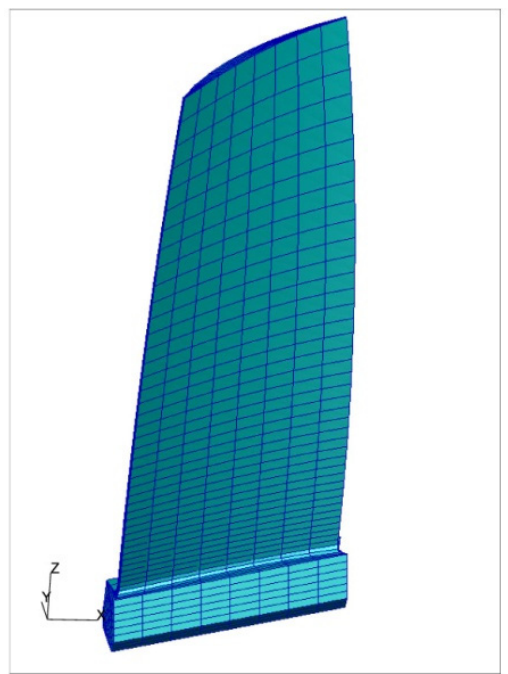

Fig. 9 Finite element model of the compressor blade.

The compressor blade is manufactured out of EI-736 material [16]. This alloy is martensitic steel with good strength, ductility, and fracture toughness. These properties along with good weldability and formability account for its wide use in aerospace applications. The yield point of EI-736 alloy in temperature $0^{\circ} \mathrm{C}$ is $820 \mathrm{MPa}$, while the UTS (ultimate tensile strength) - $969 \mathrm{MPa}$. The analysis, presented in this paper was performed for linear-elastic disc and blade materials. 
The ABAQUS v. 6.7 [17] program was used for stress analysis of the undamaged compressor blade. The nonlinear (incremental), Newton-Raphson method was applied. For all results, Megapascal (MPa) units were used to describe the fields of stress. All numerical results are obtain for amplitude of blade tip displacement equals $2,5 \mathrm{~mm}$.

The Von Mises stress distribution does not show if the material is tension or compressed. Because of this fact, in this paper the maximum principal stress distributions were analyzed. This stress is particularly interesting from the point of view of the fatigue strength because just the tensile stresses contribute the most to the fatigue crack initiation and next to crack propagation.

The blade under vibration is periodically bent in left and right side (Fig.10). Because of fact that the cross-section of blade is non-symmetric, the stress levels under left and right deflection of blade will be quite different. In description of figures and results, the information about blade deflection will be placed. The blade for better visualization of numerical results will be shown in vertical position.

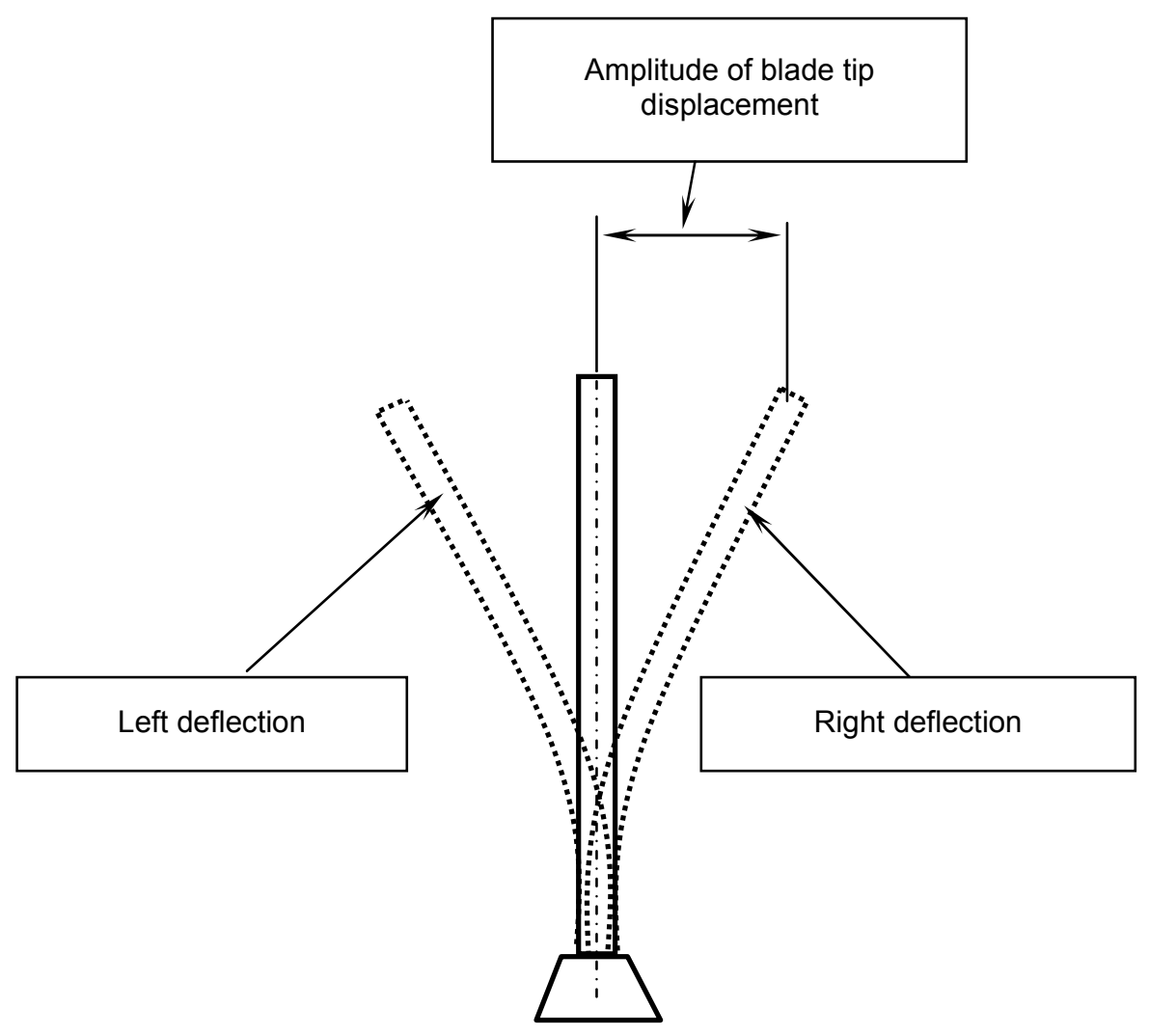

Fig.10. Passing positions of blade under vibration.

Fig. 11 shows, that the tensile stress on convex surface of blade where the cracks appeared, achieves 622-1011 MPa (for right deflection of blade). The maximum stress region (1088 MPa) is located about $1 \mathrm{~mm}$ above the blade locking piece, on central part of convex surface (Fig. 12a). Near the neutral axis of blade cross-section, the tensile stress decreases to $0 \mathrm{MPa}$. Between maximum stress region and the neutral axis, the high gradient of stresses is observed. During left deflection, the maximum tensile stress region $(934 \mathrm{MPa})$ is located near attack edge of blade (Fig. $12 b)$. 


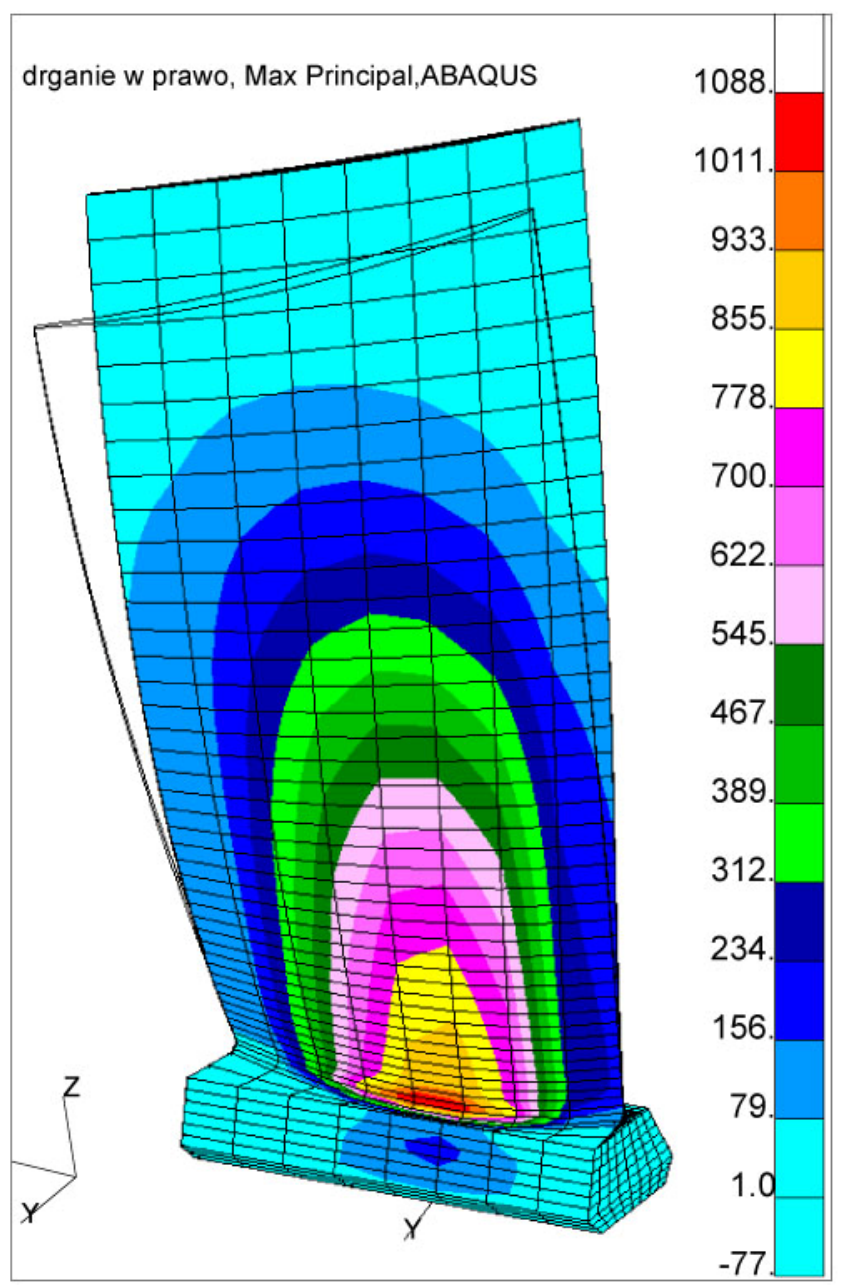

Fig. 11. Maximum principal stress distribution for blade during resonance (mode I, transverse vibrations, amplitude of blade tip: $2,5 \mathrm{~mm}$, right deflection of blade.
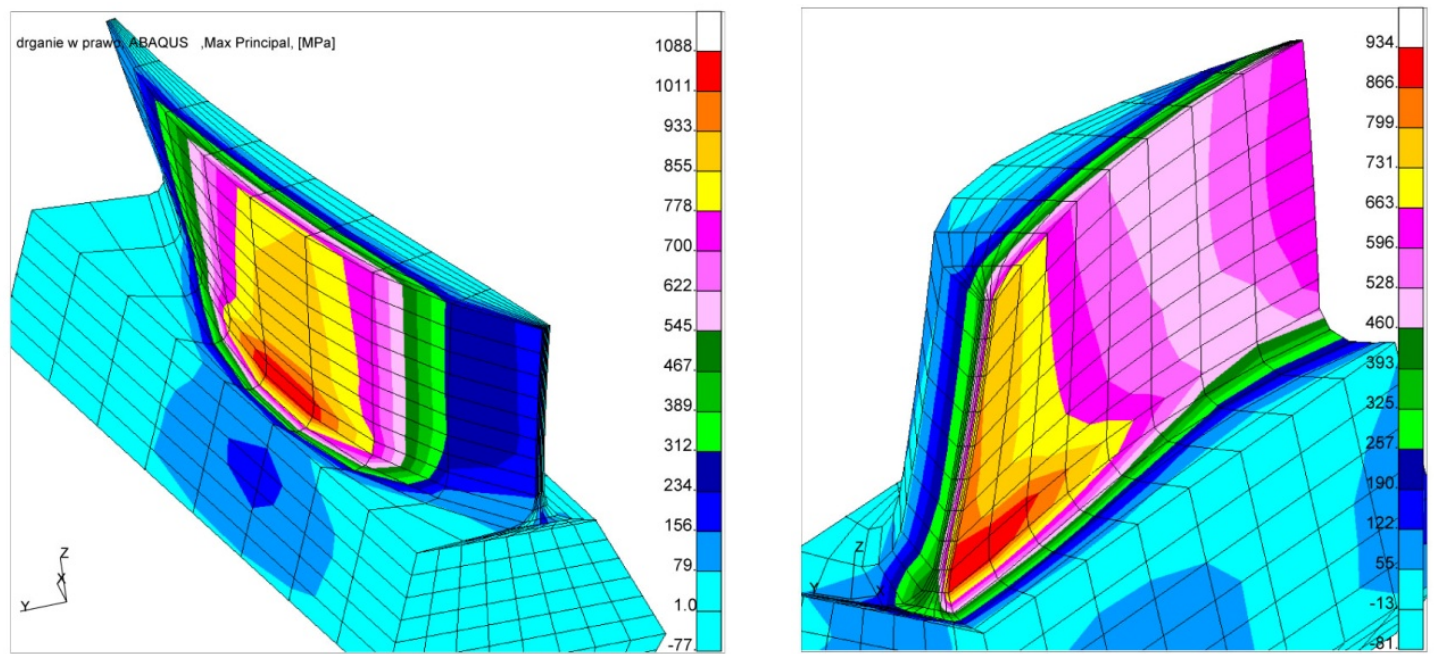

Fig. 12. Maximum principal stress distribution during resonance (mode I, transverse vibrations, amplitude of blade tip: $2,5 \mathrm{~mm}$,). Cross-section in the crack zone before crack initiation. Right (a) and left (b) deflection of blade. 


\section{CONCLUSIONS.}

In this study the experimental and numerical analysis were performed to investigate both crack propagation and damage process of the compressor blade subjected to high cycle fatigue. The blades during investigations were tested in artificially created condition. By specify one load component, it was possible to obtain the number of load cycles to the crack initiation and total fatigue life of blade subjected only to vibration. The visual examination showed that the cracks were initiated on the convex surface of profile, $2 \div 10 \mathrm{~mm}$ above the blade locking piece. In tested blade, crack was initiated after $4 \times 10^{5}$ total number of cycles. After initiation, the crack was developed inside the structure (rapid increase of size $b$ presented in Fig. 6). The total fatigue life of compressor blade was equal $9,97 \times 10^{5}$ number of load cycles. A relatively large amplitude of vibration (2,5 $\mathrm{mm}$ at beginning of test and $1 \mathrm{~mm}$ at finish) caused that high crack growth rate was observed, especially when crack size a (Fig 6,7) was more then $10 \mathrm{~mm}$. The crack origin zone was not covered by corrosion product. For better visualization of the crack front in early and advanced stage of fracture, the blades with preliminary fatigue cracks were statically ruptured with use the testing machine.

Analysis of numerical results showed, that a main reason for fatigue cracks appearing was high stress occurred during blade resonance. Moreover in the cross-section of blade high stress gradient was observed.

The general remark can be formulated based on results of this analysis: the transverse vibrations can be very dangerous for compressor blades because of high stress occurred during blade resonance. In consequence the crack cans rapidly growth to the critical size leaded to failure of engine. For these reasons, the work of engine blades in resonance condition should be avoided.

\section{ACKNOWLEDGEMENTS}

This work was supported by Polish Ministry of Science and Higher Education (Project no. NN 504346736). The author would like to thank Prof. J Sieniawski and K. Kubiak-D.Sc. for possibility of performing of the fatigue investigations in Research and Development Laboratory for Aerospace Materials of Rzeszów University of Technology. 


\section{REFERENCES}

[1] Lourenço, N. J., Graça, M. L. A., Franco, L. A. L., \& Silva, O. M. M. (2008). Fatigue failure of a compressor blade. Engineering Failure Analysis. 15, 1150-1154.

[2] Kermanpur, A.; Sepehri Ami, H.; Ziaei-Rad, S., Nourbakhshnia, N., Mosaddeghfar, M. (2008). Failure analysis of Ti6A14V gas turbine compressor blades, Engineering Failure Analysis. 15, 1052-1064.

[3] Silveira, E., Atxaga, G., \& Irisarri, A.M. (2008). Failure analysis of a set of compressor blades. Engineering Failure Analysis. 15, 666-674.

[4] Poznanska, A., Sniezek, M., \& Wierzbinska, M. (2003). Pitting corrosion - main factor generating fracture of the compressor of aeroengine blades under operation [in Polish]. In: Proceedings of the IX Conference - Turbomachinery. Rzeszow.

[5] Troshchenko, V.T., \& Prokopenko, A.V. (2000). Fatigue strength of gas turbine compressor blades. Engineering Failure Analysis. 7, 209-220.

[6] Park, M., Hwang, Young-H., Choi, Y.-S, \& Kim, T.-G. (2002). Analysis of a J69-T-25 engine turbine blade fracture, Engineering Failure Analysis. 9, 593-601.

[7] Song K.-S., Kim, S.-G., Jung, D., \& Hwang Y.-H. (2007). Analysis of the fracture of a turbine blade on a turbojet engine, Engineering Failure Analysis. 14, 877-883.

[8] Vardar N., Ekerim A. (2007). Failure analysis of gas turbine blades in a thermal power plant. Engineering Failure Analysis. 14, 743-749.

[9] Xu X., \& Yu Z. (2007). An investigation on the failed blades in a locomotive turbine. Engineering Failure Analysis. 14, 1322-1328.

[10] Song, K., Kim, S., Jung, D., \& Hwang,Y. (2007). Analysis of the fracture of a turbine blade on a turbojet engine Engineering Failure Analysis. 14, 877-883.

[11] Xie, Y. et al. (2006). Analysis of superalloy turbine blade tip cracking during service, Engineering Failure Analysis, 13, 1429-1436.

[12] Witek, L. (2006). Failure analysis of turbine disc of an aero engine, Engineering Failure Analysis, 13(1). Elsevier Science.

[13] Witek, L., Kowalski, T., \& Mamrowicz, J. (2007). Numerical stress and fatigue analysis of the first stage of turbine for helicopter engine. In: Proceedings of the International Conference on Aeronautical Fatigue, Napoli.

[14] Witek, L, Poznańska, A., \& Wierzbińska, M. Fracture analysis of a compressor blade of an helicopter engine. Engineering Failure Analysis. 16(5), 1616-1622.

[15] MSC Corporation. (2004). MSC-PATRAN User_s Manual, ver. 2004. Los Angeles: MSC Corporation.

[16] Michailov, P. B. (1961). Sprawocznik po Metaliczeskim Matierialam Turbino- i Motorostroenija, Petersburg.

[17] Dessault Systems. (2007). ABAQUS Users Manual, ver. 6.7. Abaqus Inc. 